\title{
Haplotype analysis of ApoAl gene and sepsis-associated acute lung injury
}

\author{
Jian Hao and Xian-Di He
}

\begin{abstract}
Background: Apolipoprotein A1 (ApoA1) is the major apoprotein constituent of high density lipoprotein (HDL) which exerts innate protective effects in systemic inflammation. However, its role in the acute lung injury (ALI) has not been well studied. In the present study we investigated the association between polymorphisms of ApoA1 gene and ALI in a Chinese population.

Methods: Three polymorphisms of the ApoA1 gene (rs11216153, rs2070665, and rs632153) were genotyped by TaqMan method in 290 patients with sepsis-associated ALI, 285 patients sepsis alone and 330 age- and sex-matched healthy controls.

Results: We found rs11216153 polymorphism of ApoA1 was associated with ALI, the GG genotype and G allele was common in the ALI patients $(76.9 \%, 88.1 \%$, respectively) than both in the control subjects $(55.8 \%, 75.8 \%$, respectively) and in the sepsis alone patients (58.2\%, 78.4\%, respectively). Haplotype consisting of these three SNPs strengthened the association with ALI susceptibility. The frequency of haplotype GTG in the ALI samples was significantly higher than that in the healthy control group ( $\mathrm{OR}=2.261,95 \% \mathrm{Cl}: 1.735 \sim 2.946, \mathrm{P}<0.001)$ and the sepsis alone group ( $\mathrm{OR}=1.789,95 \% \mathrm{Cl}: 1.373 \sim 2.331 . \mathrm{P}<0.001)$. Carriers of the haplotype $T \mathrm{G}$ had a lower risk for ALI compared with healthy control group (OR $=0.422,95 \% \mathrm{Cl}: 0.310 \sim 0.574, \mathrm{P}<0.001)$ and sepsis alone group ( $\mathrm{OR}=0.491,95 \% \mathrm{Cl}: 0.356 \sim 0.676, \mathrm{P}<0.001)$.
\end{abstract}

Conclusions: These results indicated that genetic variants in the ApOA1 gene might be associated with susceptibility to sepsis-associated ALI in Han Chinese population.

Keywords: ApoA1, Polymorphism, Haplotype, Acute lung injury

\section{Introduction}

Acute lung injury (ALI) and its more severe form, the acute respiratory distress syndrome (ARDS), are syndromes of acute respiratory failure that are characterized by acute pulmonary edema and lung inflammation. ALI remains an important cause of death in the intensive care units (ICU) and few specific therapies are available [1]. Although sepsis, pneumonia, aspiration, trauma, pancreatitis and multiple transfusion are recognized as the most common causes of ALI, only a small fraction of patients with these risk factors develop ALI [2]. Clinical and epidemiological studies have supported the hypothesis that genetic factors might play a part in the development and outcome of ALI [3-10]. Identification

\footnotetext{
* Correspondence: hexiandi37@yeah.net

*CU Departments, First Affiliated Hospital of Bengbu Medical College, Bengbu 233004, China
}

of genetic variants may provide new insight into the molecular pathogenesis of ALI and lead to the development of new diagnostic and therapeutic targets [6]. The pathogenetic basis of ALI is incompletely understood.

However, emerging evidence has suggested that the severity and outcome of ALI depend significantly on systemic inflammatory response [11]. Apolipoprotein A1 (ApoA1) is the major apoprotein constituent of high density lipoprotein (HDL) which exerts innate protective effects in systemic inflammation [12]. However, its role in the acute lung injury (ALI) has not been well studied. Previous study [13] suggested that one variant residing in the ApoA1 gene, which involves a guanine to adenine transition 75 base pairs (bp) upstream from the start of transcription $(\mathrm{G}-75 \mathrm{~A})$ and destroys a site for the MspI restriction enzyme, was associated with ALI after cardiopulmonary bypass surgery. In their study, the authors only 
selected one single nucleotide polymorphism (-75 G > A) to perform a case-control study. And this is a hospital based case-control study, the selection bias cannot be avoidable and the subjects may not be representative of the general population.

In the present study, we established haplotypes of ApoA1 gene consisting of 3 SNPs (rs11216153, rs2070665, and rs632153) and to assess the relationship between these haplotypes and ALI in a Chinese population.

\section{Material and methods}

\section{Patients}

The present study was reviewed and approved by the Ethics Study Board of First Affiliated Hospital of Bengbu Medical College. Informed written consent was obtained from all subjects or from their legal surrogates before enrollment. Definitions of sepsis and ALI were in accordance with the American College of Chest Physicians/ Society of Critical Care Medicine Consensus Conference [14] and the American-European Consensus Conference statements (AECC) [15].

All sepsis subjects enrolled had either severe sepsis or septic shock. All patients were selected from the Emergency and Respiratory ICUs at First Affiliated Hospital of Bengbu Medical College, and were treated according to the Surviving Sepsis Campaign guidelines [16]. Exclusion criteria included age below 18 years, severe chronic respiratory disease, severe chronic liver disease (defined as a Child-Pugh score of $>10$ ), using of high-dose immunosuppressive therapy and AIDS patients. All sepsis patients were screened daily for ALI/ARDS development and those who fulfilled the AECC criteria for ALI/ARDS were considered as ALI cases, which included ALI and ARDS patients; whereas those patients who did not develop ALI/ARDS during hospital stay were considered as sepsis alone patients. Baseline characteristics of all patients were obtained during ICU stay. Sex- and agematched controls were selected from healthy blood donors. We selected the control subjects aged 55-66 years, which was matched to the patients group. There are not significant difference between the control subjects and the ALI patients in age and in sex.

Questionnaires including smoking, chronic illness and the history of ALI or sepsis were obtained from all control subjects. Healthy controls were defined as individuals without any recent acute illness, any chronic illness and a history of ALI or sepsis. To reduce the potential confounding from ethnic backgrounds, we only enrolled people with self-reported origin of central Han Chinese.

\section{Genotyping}

There are 156 SNPs for the human ApoA1 gene listed in the National Center for Biotechnology Information SNP

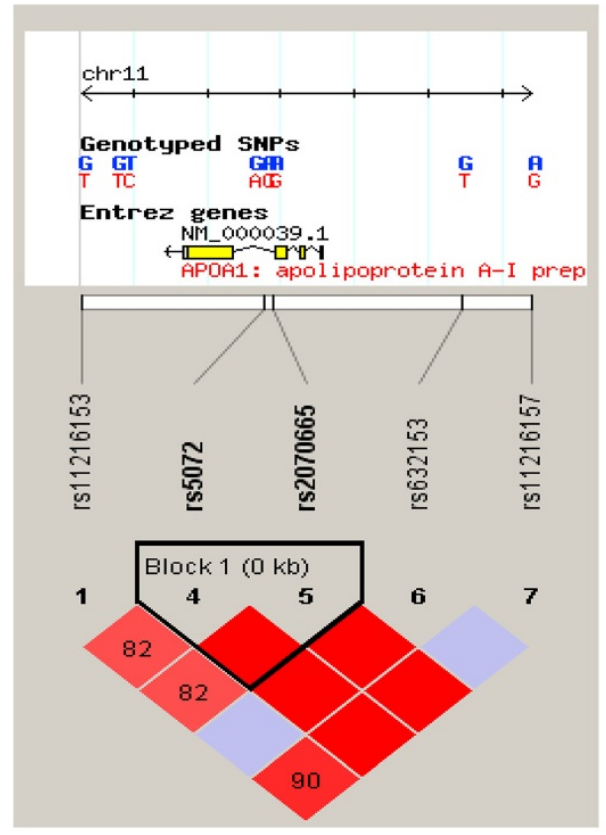

A

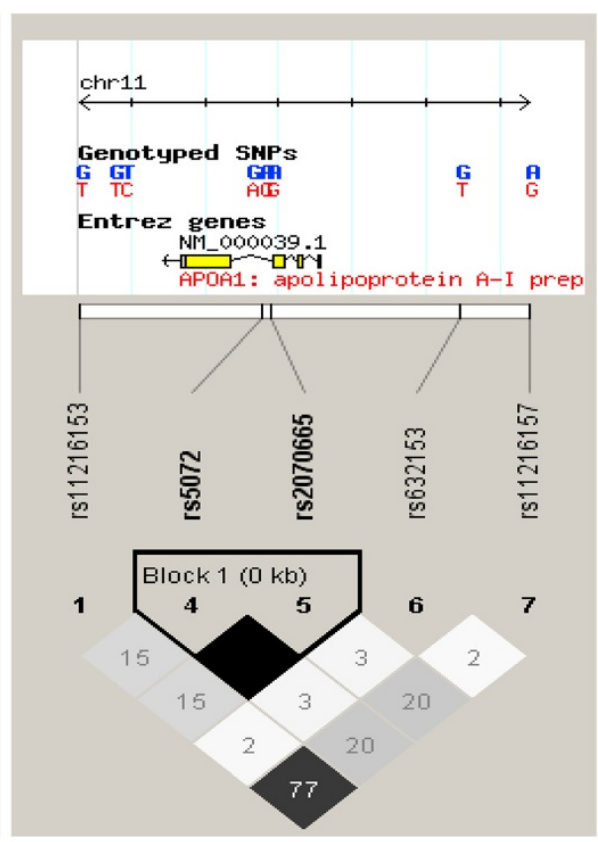

B

Figure 1 Genetic variation at human ApoA1 gene. Using the Haploview 4.2 software and the HapMap phrase II database, we scanned 5 genotyped single-nucleotide polymorphisms (SNPS) in Chinese Han. Linkage disequilibrium (LD) blocks across the locus in Chinese Han. LD block derived by solid spline method in Haploview 4.2. LD value shown: (A) $\left|D^{\prime}\right| \times 100 ;\left|D^{\prime}\right|$ colour scheme: $\left|D^{\prime}\right|=0$ : white; $0<\left|D^{\prime}\right|<1$ : shades of pink; $\left|D^{\prime}\right|=1$ : red; (B) $r^{2} \times 100 ; r^{2}$ colour scheme: $r^{2}=0$ : white; $0<r 2<1$ : shades of grey; $r^{2}=1$ : black. 
Table 1 Demographic and clinical characteristics of subjects

\begin{tabular}{|c|c|c|c|c|}
\hline & Healthy controls & ALI patients & Sepsis alone patients & $P$ value \\
\hline Number & 330 & 290 & 285 & N.A \\
\hline Age, year & $65.3 \pm 10.2$ & $63.8 \pm 11.9$ & $64.1 \pm 10.7$ & 0.643 \\
\hline Male (\%) & $186(56.4)$ & $172(59.3)$ & 170 (59.6) & 0.877 \\
\hline BMI $\left(\mathrm{kg} \cdot \mathrm{m}^{-2}\right)$ & $21.1 \pm 4.4$ & $23.3 \pm 4.8$ & $23.1 \pm 5.8$ & 0.452 \\
\hline Diabetes (\%) & 0 & $56(19.3)$ & $51(17.9)$ & 0.078 \\
\hline Liver cirrhosis (\%) & 0 & $16(5.5)$ & $13(4.6)$ & 0.176 \\
\hline Smoker (\%) & 118 (34.2) & 107 (36.9) & $102(35.8)$ & 0.223 \\
\hline \multicolumn{5}{|l|}{ Sepsis insult (\%) } \\
\hline Lung (\%) & N.A & $265(91.4)$ & $262(91.9)$ & 0.989 \\
\hline Abdomen (\%) & N.A & $7(2.4)$ & $8(2.8)$ & 0.997 \\
\hline UTI (\%) & N.A & $5(1.7)$ & $4(1.4)$ & 0.879 \\
\hline Bloodstream (\%) & N.A & $11(3.8)$ & $10(3.5)$ & 0.987 \\
\hline Other (\%) & N.A & $2(0.7)$ & $1(0.4)$ & 0.774 \\
\hline
\end{tabular}

database (http://www.ncbi.nlm.nih.gov/SNP). As shown in Figure 1, using the Haploview 4.2 software and the HapMap phrase II database, we obtained three tagging SNPs (rs11216153, rs2070665, and rs632153) for Chinese Han using minor allele frequency (MAF) $\geq 0.05$ and linkage disequilibrium patterns with $\mathrm{r}^{2} \geq 0.6$ as a cutoff.

Genomic DNA was extracted from the peripheral blood leukocytes using a DNA extraction Kit (Beijing Bioteke Co. Ltd). Genotyping was confirmed by TaqMan method as described previously [17].

\section{Statistical analysis}

The SPSS 17.0 for windows was used for the statistical analysis. For each polymorphism, Hardy-Weinberg equilibrium was assessed using the standard $\chi^{2}$ test or Fisher's exact test. Genotype frequencies in cases and controls were compared by $x^{2}$ tests. The genotype-specific risks were estimated as odds ratios (ORs) and it's 95\% CI. Based on the genotype data of the genetic variations, we performed linkage disequilibrium (LD) analysis and haplotype-based case-control analysis, using the SHEsis software (http://analysis2.bio-x.cn/myAnalysis.php) [18,19].

Table 2 Genotype distribution of ApoAl tag SNPs between case and control subjects

\begin{tabular}{|c|c|c|c|c|c|c|}
\hline SNPs & Genotype and allele & Control $(n=330)$ & ALI patients $(n=290)$ & Sepsis alone patients $(n=285)$ & $P^{a}$ & $P^{b}$ \\
\hline \multirow[t]{5}{*}{ rs11216153 } & GG & $184(0.558)$ & $223(0.769)$ & $166(0.582)$ & $<0.001$ & $<0.001$ \\
\hline & GT & $132(0.400)$ & $65(0.224)$ & $115(0.404)$ & & \\
\hline & $\pi$ & $14(0.042)$ & $2(0.007)$ & $4(0.014)$ & & \\
\hline & G & 0.758 & 0.881 & 0.784 & $<0.001$ & $<0.001$ \\
\hline & T & 0.242 & 0.119 & 0.216 & & \\
\hline \multirow[t]{5}{*}{ rs2070665 } & $\mathrm{CC}$ & $101(0.306)$ & $80(0.276)$ & $83(0.291)$ & 0.594 & 0.812 \\
\hline & $C T$ & $181(0.548)$ & $161(0.555)$ & $159(0.558)$ & & \\
\hline & $\pi$ & $48(0.146)$ & $49(0.169)$ & $43(0.151)$ & & \\
\hline & C & 0.580 & 0.553 & 0.570 & 0.340 & 0.567 \\
\hline & $\mathrm{T}$ & 0.420 & 0.447 & 0.430 & & \\
\hline \multirow[t]{5}{*}{ rs632153 } & GG & $281(0.851)$ & $246(0.848)$ & $241(0.846)$ & 0.879 & 0.986 \\
\hline & GT & $47(0.142)$ & $43(0.148)$ & $43(0.150)$ & & \\
\hline & $\pi$ & $2(0.007)$ & $1(0.004)$ & $1(0.004)$ & & \\
\hline & G & 0.923 & 0.922 & 0.921 & 0.983 & 0.931 \\
\hline & T & 0.077 & 0.078 & 0.079 & & \\
\hline
\end{tabular}

$P^{a}:$ ALI vs. control; $P^{b}:$ ALI vs. Sepsis alone patients. 
Table 3 Distribution of haplotypes (ALI patients vs. healthy control)

\begin{tabular}{lllll}
\hline Haplotype & ALI patients & Control & $P$ & OR $(\mathbf{9 5} \% \mathbf{C l})$ \\
\hline G C G & $276.00(0.476)$ & $332.00(0.503)$ & 0.339 & $0.897[0.717 \sim 1.121]$ \\
G C T & $45.00(0.078)$ & $51.00(0.077)$ & 0.983 & $1.004[0.662 \sim 1.525]$ \\
G T G & $190.00(0.328)$ & $117.00(0.177)$ & $<0.001$ & $2.261[1.735 \sim 2.946]$ \\
T T G & $69.00(0.119)$ & $160.00(0.242)$ & $<0.001$ & $0.422[0.310 \sim 0.574]$ \\
\hline
\end{tabular}

In the haplotype-based case-control analysis, haplotypes with a frequency of $<0.03$ were excluded. Statistical significance was established at $\mathrm{P}<0.05$.

\section{Results}

\section{Characteristics of the study population}

The baseline characteristics of the study population are shown in Table 1. The primary source of infection was the lungs, involving $91.1 \%$ of the combined sample of sepsis alone and ALI patients. There was no significant difference in age, gender, BMI, diabetes, liver cirrhosis and history of smoking between ALI patients and sepsis alone patients $(\mathrm{P}>0.05)$.

\section{Associations of the ApoA1 gene SNPs with ALI risk}

Table 2 shows the distribution of the genotypes and alleles of these 3 SNPs. The genotype distribution of each SNP did not show significant difference from the HardyWeinberg equilibrium values (data not shown). We found rs11216153 polymorphism of ApoA1 was associated with ALI, the GG genotype and G allele was common in the ALI patients (76.9\%, 88.1\%, respectively) than both in the control subjects $(55.8 \%, 75.8 \%$, respectively, $\mathrm{P}<0.001)$ and in the sepsis alone patients $(58.2 \%, 78.4 \%$, respectively, $\mathrm{P}<0.001)$. However, we did not find any association of rs2070665 and rs632153 with ALI.

\section{Associations of the ApoA1 gene haplotypes with ALI risk} As shown in Table 3 and Table 4, the frequency of haplotype GTG in the ALI samples was significantly higher than that in the healthy control group $(\mathrm{OR}=2.261,95 \% \mathrm{CI}$ : $1.735 \sim 2.946, \mathrm{P}<0.001)$ and the sepsis alone group (OR $=$ 1.789, 95\% CI: $1.373 \sim 2.331 . \mathrm{P}<0.001)$. Carriers of the haplotype TTG had a lower risk for ALI compared with healthy control group ( $\mathrm{OR}=0.422,95 \% \mathrm{CI}: 0.310 \sim 0.574$, $\mathrm{P}<0.001)$ and sepsis alone group $(\mathrm{OR}=0.491,95 \% \mathrm{CI}$ : $0.356 \sim 0.676, \mathrm{P}<0.001)$.

\section{Discussion}

In the present study, we found $A p o A 1$ gene polymorphisms and haplotypes were significant associated with ALI risk in a Chinese population. Some studies have been performed to find an association of genetic polymorphisms and ALI [20]. A prospective case-control study found that $-607 \mathrm{C} / \mathrm{C}$ genotype in IL-18 gene played a pivotal role in the development of ALI in Chinese Han population [21]. Another case-control study found that the IL-6 -572 polymorphism was associated with ALI [22]. Several studies have suggested that pre-B-cell colonyenhancing factor (PBEF) gene polymorphisms were associated with susceptibility and prognosis of ALI [23,24]. The plasminogen activator inhibitor-1 (PAI-1) 4G allele was associated with worse outcome in ALI/ARDS [25]. A prospective cohort demonstrated that the AC genotype at position -1221 in the NQO1 gene caused decreased transcription and was associated with a lower incidence of ALI following major trauma [26]. In a nested case-control study, patients with the NRF2 -617 A allele had a significantly higher risk for developing ALI after major trauma [27]. A case-control study found that myosin light chain kinase (MYLK) genetic variants were associated with increased risk of sepsis-associated ALI [28].

The ApoA1 gene has recently been linked to many other diseases. A comparative study found that carrying the ApoA1 -75 A allele could confer a higher risk of hyperlipidemia in obese children [29]. A prospective case-control study found that the ApoA1 -75 G/A polymorphism influenced cholesterol metabolism [30]. A pilot study in a north Indian population suggested that the ApoA1-75 G allele might be a susceptibility allele for myocardial infarction [31].

In our study, we genotyped 3 SNPs in $A p o A 1$ in Chinese participants and assessed the association between ApoA1 and ALI using a haplotype-based case-control analysis. The rs11216153 significantly differed between ALI patients and control participants, indicating that the risk of ALI is increased in participants with the $G$ allele of rs11216153. Morris and Kaplan found that for genes with multiple susceptibilities, analysis based on haplotypes has advantages over analysis based on individual SNPs [32]. Consequently, in the present study, we successfully established haplotypes for the ApoA1 gene from the different combination of the 3 SNPs. The frequency of the GTG was associated with increased risk for

Table 4 Distribution of haplotypes (ALI patients vs. Sepsis alone patients)

\begin{tabular}{lllll}
\hline Haplotype & ALI patients & Sepsis alone patients & $\boldsymbol{P}$ & OR (95\% Cl) \\
\hline G C G & $276.00(0.476)$ & $279.99(0.491)$ & 0.602 & $0.940[0.746 \sim 1.185]$ \\
G C T & $45.00(0.078)$ & $45.00(0.079)$ & 0.931 & $0.981[0.638 \sim 1.509]$ \\
G T G & $190.00(0.328)$ & $122.01(0.214)$ & $<0.001$ & $1.789[1.373 \sim 2.331]$ \\
T T G & $69.00(0.119)$ & $122.99(0.216)$ & $<0.001$ & $0.491[0.356 \sim 0.676]$ \\
\hline
\end{tabular}


ALI. However, the TTG was associated with decreased risk for ALI.

Although we found rs11216153 was associated with ALI risk in the present study, this SNP was located in the non-coding region of ApoA1. Given that this SNP was tag SNP, it is more likely that rs11216153 is tagging other common or rare variants of the ApoA1 gene associated with ALI. Another possibility is that the association might be due to LD with variants from nearby genes. Exhaustive resequencing is required to find or rule out the possibility of an as-yet-unidentified causal SNP in LD with rs11216153. And further functional studies are needed to investigate whether the variants have an effect on ApoA1 mRNA stability and translatability.

This study has a number of strengths. First, a sepsis without ALI group was used for comparison to exclude the possibility of a false association with sepsis. Second, to minimize racial admixture, we focused on central Han Chinese patients, which could be regarded as one single homogenous population [23,24]. Third, to reduce the heterogeneous etiologies for ALI, the present study only included patients whose primary etiology for ALI was sepsis.

Some limitations of this study should be noted. First of all, these results should be interpreted with caution because the population was only from China, which reduces the possibility of confounding from ethnicity, so it does not permit extrapolation of the results to other ethnic groups. Second, the sample size of this study is relatively small, which may not have enough statistical power to explore the real association. Third, this is a hospital based case-control study, so the selection bias cannot be avoidable and the subjects may not be representative of the general population.

\section{Conclusion}

In conclusion, the present results indicate that ALI is associated with the ApoA1 gene polymorphisms. The GTG haplotype appear to be a risk genetic marker and the TTG haplotypes might be protective factor of ALI in Chinese people.

\section{Competing interests}

The authors declared no competing interests exist.

\section{Authors' contributions}

$\mathrm{JH}$ and $\mathrm{XDH}$ carried out the molecular genetic studies and drafted the manuscript. JH carried out the genotyping. XDH performed the statistical analysis. Both authors read and approved the final manuscript.

\section{Acknowledgement}

We appreciate the help from Dr. Chen Shi, Shanghai Institute of Cell Research, Chinese Academy of Medical Sciences.

Received: 8 February 2014 Accepted: 10 April 2014

Published: 13 May 2014

\section{References}

1. Matthay MA, Zimmerman GA, Esmon C, Bhattacharya J, Coller B, Doerschuk CM, Floros J, Gimbrone MA Jr, Hoffman E, Hubmayr RD, Leppert M, Matalon S, Munford R, Parsons P, Slutsky AS, Tracey KJ, Ward P, Gail DB, Harabin AL: Future research directions in acute lung injury: summary of a NationalHeart, Lung, and Blood Institute working group. Am J Respir Crit Care Med 2003, 167(7):1027-1035.

2. Ware $L B$, Matthay MA: The acute respiratory distress syndrome. $N$ Engl J Med 2000, 342(18):1334-1349.

3. Adamzik M, Frey U, Sixt $S$, Knemeyer $L$, Beiderlinden $M$, Peters J, Siffert W: ACE I/D but not AGT (-6)A/G polymorphism is a risk factor for mortality in ARDS. Eur Respir J 2007, 29(3):482-488.

4. Arcaroli J, Sankoff J, Liu N, Allison DB, Maloney J, Abraham E: Association between urokinase haplotypes and outcome from infection-associated acute lung injury. Intensive Care Med 2008, 34(2):300-307.

5. Su L, Zhai R, Sheu CC, Gallagher DC, Gong MN, Tejera P, Thompson BT, Christiani DC: Genetic variants in the angiopoietin-2 gene are associated with increased risk of ARDS. Intensive Care Med 2009, 35(6):1024-1030.

6. Jin X, Hu Z, Kang Y, Liu C, Zhou Y, Wu X, Liu J, Zhong M, Luo C, Deng L, Deng Y, Xie X, Zhang Z, Zhou Y, Liao X: Association of IL-10-1082 G/G genotype with lower mortality of acute respiratory distress syndrome in a Chinese population. Mol Biol Rep 2012, 39:1-4.

7. Garcia JG: Searching for candidate genes in acute lung injury: SNPs, Chips and PBEF. Trans Am Clin Climatol Assoc 2005, 116:205-219.

8. Lagan AL1, Quinlan GJ, Mumby S, Melley DD, Goldstraw P, Bellingan GJ, Hill MR, Briggs D, Pantelidis P, du Bois RM, Welsh Kl, Evans TW: Variation in iron homeostasis genes between patients with ARDS and healthy control subjects. Chest 2008, 133(6):1302-1311.

9. Medford AR, Keen LJ, Bidwell JL, Millar AB: Vascular endothelial growth factor gene polymorphism and acute respiratory distress syndrome. Thorax 2005, 60(3):244-248.

10. Flores C, Pino-Yanes Mdel M, Villar J: A quality assessment of genetic association studies supporting susceptibility and outcome in acute lung injury. Crit Care 2008, 12(5):R130.

11. Schwartz MD, Moore EE, Moore FA, Shenkar R, Moine P, Haenel JB, Abraham E: Nuclear factor-kappa B is activated in alveolar macrophages from patients with acute respiratory distress syndrome. Crit Care Med 1996, 24(8):1285-1292.

12. Albahrani Al, Usher JJ, Alkindi M, Marks E, Ranganath L, Al-yahyaee S: ApolipoproteinA1-75 G/A (M1-) polymorphism and lipoprotein(a); anti- vs. pro-Atherogenic properties. Lipids Health Dis 2007, 6:19.

13. Tu J, Zhang B, Chen Y, Liang B, Liang D, Liu G, He F: Association of apolipoprotein $\mathrm{A} 1-75 \mathrm{G} / \mathrm{A}$ polymorphism with susceptibility to the development of acute lung injury after cardiopulmonary bypass surgery. Lipids Health Dis 2013, 12:172

14. Cohen IL: Guidelines for the use of innovative therapies in sepsis. Crit Care Med 1993, 21:476-477.

15. Bernard GR, Artigas A, Brigham KL, Carlet J, Falke K, Hudson L, Lamy M, LeGall JR, Morris A, Spragg R: Report of the American-European consensus conference on ARDS: definitions, mechanisms, relevant outcomes and clinical trial coordination. The Consensus Committee. Intensive Care Med 1994, 20(3):225-232.

16. Dellinger RP, Levy MM, Rhodes A, Annane D, Gerlach H, Opal SM, Sevransky JE, Sprung CL, Douglas IS, Jaeschke R, Osborn TM, Nunnally ME, Townsend SR, Reinhart K, Kleinpell RM, Angus DC, Deutschman CS, Machado FR, Rubenfeld GD, Webb SA, Beale RJ, Vincent JL, Moreno R, Surviving Sepsis Campaign Guidelines Committee including the Pediatric Subgroup: Surviving Sepsis Campaign guidelines for management of severe sepsis and septic shock. Crit Care Med 2004, 32(3):858-873.

17. Xie X, Ma YT, Fu ZY, Yang YN, Ma X, Chen BD, Wang YH, Liu F: Haplotype analysis of the CYP8A1 gene associated with myocardial infarction. Clin Appl Thromb Hemost 2009, 15(5):574-580.

18. Shi YY, He L: SHEsis, a powerful software platform for analyses of linkage disequilibrium, haplotype construction, and genetic association at polymorphism loci. Cell Res 2005, 15(2):97-98.

19. Li Z, Zhang Z, He Z, Tang W, Li T, Zeng Z, He L, Shi Y: A partition-ligationcombination-subdivision EM algorithm for haplotype inference with multiallelic markers: update of the SHEsis. Cell Res 2009, 19:519-523. http://analysis.bio-x.cn

20. Reddy AJ, Kleeberger SR: Genetic polymorphisms associated with acute lung injury. Pharmacogenomics 2009, 10:1527-1539. 
21. Chen S, Xu L, Tang J: Association of interleukin 18 gene polymorphism with susceptibility to the development of acute lung injury after cardiopulmonary bypass surgery. Tissue Antigens 2010, 76:245-249.

22. Wang JF, Bian JJ, Wan XJ, Zhu KM, Sun ZZ, Lu AD: Association between inflammatory genetic polymorphism and acute lung injury after cardiac surgery with cardiopulmonary bypass. Med Sci Monit 2010 16:CR260-CR265.

23. Liu Y, Shao Y, Yu B, Sun L, LV F: Association of PBEF gene polymorphisms with acute lung injury, sepsis, and pneumonia in a northeastern Chinese population. Clin Chem Lab Med 2012, 50:1917-1922.

24. Bajwa EK, Yu CL, Gong MN, Thompson BT, Christiani DC: Pre-B-cell colonyenhancing factor gene polymorphisms and risk of acute respiratory distress syndrome. Crit Care Med 2007, 35:1290-1295.

25. Tsangaris I, Tsantes A, Bonovas S, Lignos M, Kopterides P, Gialeraki A, Rapti E, Orfanos S, Dimopoulou I, Travlou A, Armaganidis A: The impact of the PAI-1 4G/5G polymorphism on the outcome of patients with ALI/ARDS. Thromb Res 2009, 123:832-836.

26. Reddy AJ, Christie JD, Aplenc R, Fuchs B, Lanken PN, Kleeberger SR: Association of human NAD(P)H: quinone oxidoreductase 1 (NQO1) polymorphism with development of acute lung injury. J Cell Mol Med 2009, 13:1784-1791.

27. Marzec JM, Christie JD, Reddy SP, Jedlicka AE, Vuong H, Lanken PN, Aplenc R, Yamamoto T, Yamamoto M, Cho HY, Kleeberger SR: Functional polymorphisms in the transcription factor NRF2 in humans increase the risk of acute lung injury. FASEB J 2007, 21:2237-2246.

28. Gao L1, Grant A, Halder I, Brower R, Sevransky J, Maloney JP, Moss M, Shanholtz C, Yates CR, Meduri GU, Shriver MD, Ingersoll R, Scott AF, Beaty TH, Moitra J, Ma SF, Ye SQ, Barnes KC, Garcia JG: Novel polymorphisms in the myosin light chain kinase gene confer risk for acute lung injury. Am J Respir Cell Mol Biol 2006, 34:487-495.

29. Toptas B, Gormus U, Ergen A, Gurkan H, Kelesoglu F, Darendeliler F, Bas F, Dalan AB, lzbirak G, Isbir T: Comparison of lipid profiles with APOA1 Mspl polymorphism in obese children with hyperlipidemia. In Vivo 2011, 25:425-430

30. Smach MA, Edziri H, Charfeddine B, Ben Othman L, Lammouchi T, Ltaief A, Nafati S, Dridi H, Bennamou S, Limem K: Polymorphism in apoA1 influences high-density lipoprotein cholesterol levels but is not a major risk factor of alzheimer's disease. Dement Geriatr Cogn Dis Extra 2011, 1:249-257.

31. Dawar R, Gurtoo A, Singh R: Apolipoprotein A1 gene polymorphism (G-75A and C $+83 \mathrm{~T}$ ) in patients with myocardial infarction: a pilot study in a north Indian population. Am J Clin Pathol 2010, 134:249-255.

32. Morris RW, Kaplan NL: On the advantage of haplotype analysis in the presence of multiple disease susceptibility alleles. Genet Epidemiol 2002, 23(3):221-233.

doi:10.1186/1476-511X-13-79

Cite this article as: Hao and He: Haplotype analysis of ApoAl gene and sepsis-associated acute lung injury. Lipids in Health and Disease 2014 13:79.

\section{Submit your next manuscript to BioMed Central and take full advantage of:}

- Convenient online submission

- Thorough peer review

- No space constraints or color figure charges

- Immediate publication on acceptance

- Inclusion in PubMed, CAS, Scopus and Google Scholar

- Research which is freely available for redistribution

Submit your manuscript at www.biomedcentral.com/submit 